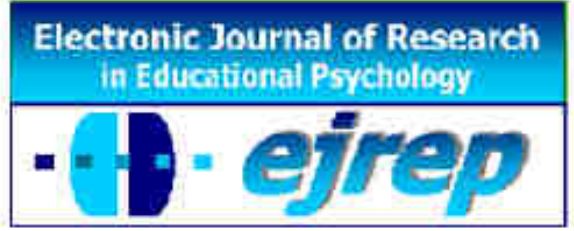

\title{
Scaffolding Young Children: The Utility of Mediation in a Classification Test
}

\section{Sara Mata ${ }^{1}$, Paul van Geert ${ }^{2}$ and Geerdina van der Aalsvoort ${ }^{3}$}

${ }^{1}$ Department of Personality, Assessment and Treatment, University of Granada (Spain)

${ }^{2}$ Department of Developmental Psychology, University of Groningen (The Netherlands)

${ }^{3}$ Saxion University of Applied Sciences (The Netherlands)

\section{Spain/ Netherlands}

Correspondence: Sara Mata. Personality, Assessment and Treatment Department, University of Granada, Campus Cartuja S/N, 18071, Spain. Phone 0034680904650 E-mail: saramata@ugr.es

(C) Education \& Psychology I+D+i and Ilustre Colegio Oficial de la Psicología de Andalucía Oriental (Spain) 


\begin{abstract}
Introduction. Studies of Dynamic Assessment of cognitive abilities reveal that young children profit from assistance while carrying out tasks that elicit cognitive effort. Dynamic assessment refers to a test format of a pretest-mediation-posttest in which the mediation phase includes scaffolding to assist the child to grasp the purpose of the task. The aim of the study was to investigate how the mediation phase proceeds. The approach is based upon a Dynamic Systems Theory that explains that the interaction between tester/assessor and testee is based upon reciprocal processes that shape both tester and testee behavior in a highly individualized situational manner.
\end{abstract}

Method. A micro-genetic methodology was applied to study the dynamics of scaffolding in the mediation phase. Transition matrices were developed in order to specify the nature and reciprocity of the dynamic system. The participants tested were four 4 year-old Dutch children attending preschool whose first language was Spanish. The test of Classification was offered. It requires from children to grasp the sorting of blocks in three categories: Color, form and size. The skill is one of the prerequisites of numeracy development.

Results. The findings show how mediation by the assessor is reciprocally adapted between each child and the assessor, generating specific patterns of dyad interaction in order to achieve the task.

Discussion and Conclusion. The scaffolding applied in the mediation phase of a Dynamic Assessment task generates significant improvements in the performance levels showed by the children in the posttest phase results. When the Dynamic System Theory is applied into the mediation phase it is possible to observe how the assessor adapts to the special necessities of the child and therefore is also modified. This fact suggests that scaffolding is a personalized process that moves along the semi-scripted mediation procedure and reveals that children not only differ with regard to their potential to learn but also differ in their ability to elicit scaffolding from the assessor.

Keywords: scaffolding, young children, Dynamic Assessment, Dynamic System Theory, mediation 


\section{Resumen}

Introducción. Los estudios de Evaluación Dinámica sobre las capacidades cognitivas revelan que los niños pequeños se benefician de la mediación (asistencia/ayuda) mientras ejecutan tareas que requieren esfuerzo cognitivo. La metodología de Evaluación Dinámica consiste en un formato de evaluación de pretest-mediación-posttest en donde la fase de mediación incluye ayudas que guían al niño en la ejecución de la tarea. El objetivo del estudio fue investigar cómo se produce la mediación. Este enfoque se basa en la Teoría de los Sistemas Dinámicos que explica cómo se produce una interacción recíproca entre el evaluado y el evaluador.

Método. Aplicamos una metodología micro-genética al estudio de la dinámica del andamiaje durante la fase de mediación. En este trabajo exponemos matrices de transición para especificar la naturaleza y reciprocidad del sistema dinámico. Los participantes fueron cuatro niños holandeses de 4 años de edad con madre era española y primer idioma el español. Todos fueron evaluados por una psicóloga española con la tarea de Clasificación. Esta tarea solicita a los niños clasificar bloques en tres categorías: color, forma y tamaño. La prueba incluye tres fases, pretest-mediación-posttest. La habilidad de clasificar es una de las condiciones de desarrollo de aritmética.

Resultados. Los resultados muestran cómo la mediación llevada a cabo por la evaluadora se vio influida por cada niño, por lo que la evaluadora generó patrones específicos de interacción con cada niño a fin de lograr mejorar su ejecución en la tarea.

Discusión. El andamiaje aplicado en la fase de mediación de una tarea de Evaluación Dinámica genera mejoras significativas en los niveles de rendimiento mostrados por los niños en los resultados en la fase posttest. Cuando la Teoría de los Sistemas Dinámicos se aplica en la fase de mediación es posible observar cómo el evaluador/a se adapta a las necesidades especiales del niño y, por lo tanto, también éste/a es modificado por él /ella. Este hecho sugiere que el andamiaje es un proceso personalizado que se mueve a lo largo del procedimiento de mediación semi-estructurada y revela que los niños no sólo difieren en lo que respecta a su potencial de aprendizaje, sino también difieren en su capacidad de obtener apoyo del evaluador.

Palabras Clave: andamiaje, niños pequeños, Evaluación Dinámica, teoría de los Sistemas Dinámicos, mediación 


\section{Introduction}

From the beginning of the Twentieth century, the assessment of intelligence, understood as a stable ability of a person, has been one of the central issues in Psychology. Nevertheless, there were some voices against that static view about intellectual abilities and, in that sense, several authors proposed the construction of new assessment instruments which enable measuring the capacity to improve, focusing generally on individuals with mental disabilities (Woodrow, 1921, quoted in Brown \& Campione, 1986; Haeussermann, 1958; Schucman, 1960; Shapiro, 1951; Volle 1957).

It was at the end of the seventies of the former century when the Dynamic Assessment (DA) procedure began to be acknowledged as an alternative to the traditional intelligence assessment through the work of Vygotsky (1978) who established the social origin of the higher mental processes. His main contribution was the concept of the Zone of Proximal Development (ZPD) which has been defined as "the distance between the actual developmental level as determined by independent problem solving and the level of potential development as determined through problem solving under adult guidance, or in collaboration with more capable peers" (Vygotsky 1978, p. 86). Taking into account this conceptualization, the ZPD makes it possible to establish which functions are in process of development and, consequently, introduce educational interventions which promote the learning.

Related to this concept is the Structural Cognitive Modifiability theory of Feuerstein who introduced the central concept of Mediated Learning Experience (MLE) that intellectual modifiability is possible whenever the testee is involved in MLE, namely, when an experienced mediator selects, organizes and presents the environmental elements to the testee, pursuing a specific educational goal (Feuerstein Klein, \& Tannenbaum, 1991). He developed a Learning Potential Assessment Device (LPAD) based on MLE.

From that point until present times DA has been applied in different contexts and with several populations, showing how people can improve their initial level of performance through including MLE into the assessment procedure (Budoff, 1987; Campione \& Brown, 1987). 
DA has been specifically developed for the assessment of young children (Lidz, 1990). The main reason is that in this stage cognitive and metacognitive abilities are being developed, therefore preschool is considered as an optimal period in which to implement DA procedures as they allow observation of how children learn and profit from the intervention with the mediator (Lidz, 2005; Lidz \& Thomas, 1987). The information thus collected is useful to develop and implement preventive actions which avoid or minimize the possible problems that children might encounter when they face curriculum contents in primary school. The DA procedure connects the assessment content with preschool curriculum contents (Calero, Carles, Mata, \& Navarro, 2010; Lidz, 1997; Tzuriel \& Haywood, 1992).

Lidz adapted the LPAD to preschool children (Lidz, 1990; Lidz \& Thomas, 1987). Her studies showed that with the mediated training inserted inside of the test children achieve a level of performance significantly bigger than the mere practice of the task (test-retest). She has worked in studies with control group (without mediation phase) showing that the mediation phase applied to the experimental groups generated significant gain levels while the control groups did not show improvements (see Lidz \& Guindis, 2003). Lidz also felt the necessity of bringing closer the assessment and the curriculum contents of young children with special needs. Trying to introduce a grade of structure into the DA of curriculum contents she developed the Application of Cognitive Functions Scale (ACFS; Lidz \& Jepsen, 2000, 2003). The ACFS measures the application of learning strategies and cognitive processes to tasks typical of the early childhood curriculum. It can be used with children from 3 to 5 years of age. Application follows the format of pretest-mediation-posttest, thus providing three types of scores: pretest (measure of performance), posttest (result after mediation), and gain (the pre-post difference) that is considered as a measure of learning potential. The mediation consists of a training phase on tasks similar to those of the pretest and posttest, including feedback on performance and instructional suggestions to guide the child toward solving the task. Relevant data concerning reliability, construct validity and discriminant validity of the ACFS are provided in several studies (Lidz, 1992, 2004; Lidz \& Van der Aalsvoort, 2005; Mata \& Calero, 2014). The Spanish adaptation of the instrument (Calero, Robles, Márquez, \& De la Osa, 2009) has been also shown to have good reliability and discriminant validity (Calero et al., 2010). The construct and discriminant validity of the ACFS for preschoolers with regular development and for children with special needs has been demonstrated in various studies (Calero et al., 2010; Calero, Fernández-Parra, et al., 2013; Calero, Mata, et al., 2013; Lidz, 2000, 2004). Several ACFS validation studies have also been conducted in different countries 
to investigate the applicability of its translated versions (Calero et al. 2010; Lidz \& Van der Aalsvoort, 2005; Van der Aalsvoort \& Lidz, 2007; Wiedl et al., 2011; Wiedl, Mata, Waldorf, \& Calero, 2014). These authors have validated this methodology with preschool children with and without mental disabilities and with immigrant children showing that in every case children were able to profit from the mediated intervention placed in the test procedure.

In this paper we focus on the actual processes taking place during the administration of the subtest of Classification, one of the six subtests of the ACFS, as it elicits the skill to classify which is one of the most powerful predictors of numeracy and academic progress in mathematics (Anders et al., 2012; Aunio \& Niemivirta, 2010). Numeracy is defined as a range of skills: estimation, correspondence one-to-one, counting abilities, numerical estimation, classification, seriation, logical operations (Desoete \& Grégoire, 2006; Passolunghi, Vercelloni, \& Schadee, 2007).

\section{The role of classification skills}

Being able to classify refers to sorting non-identical objects or events in groups of alike characteristics (Epstein, 1982, p. 161). The value of classification skills lies in being able to reduce diversity in context; memorizing information in an organized way, and applying knowledge about a specific category to interpret an example that has not been encountered before. Classification skills develop over time from becoming able to classify based upon perceptual characteristics of an object or event in a global way into specific classification that allows inference to solve problems (Quinn, 2004; Akman, Ipek, \& Uyanik, 2000). Since classification is one of the skills that a child needs to successfully master numeracy skills the ability to classify is an important clue about a child's readiness to learn mathematical skills. The task that is used in the study described below requires from the child to sort wooden blocks according to one characteristic, being either color, or form or size thus leaving out the other two characteristics of the blocks which appeal to his/her perception of the blocks as well. Since the child is also invited to carry out the three types of classification one after the other he or she is required to use his/her classification skills in a flexible way. The DA procedure not only allows assessment of the skill but also includes a mediation phase to assist the child in exploring his/her level of proximal development. In the next paragraph the phase is described more specifically to relate mediation to scaffolding. 


\section{Scaffolding as a main vehicle to allow practicing classification skills}

In the Netherlands at the age of 4 most children have entered primary school and supposedly already have a general basic knowledge of early numeracy based on informal learning at home and in child care settings (Ensing, van der Aalsvoort, van Geert, \& Voet, 2014; Krajewski \& Schneider, 2009a; Van den Heuvel-Panhuizen, \& Wijers, 2005). Nevertheless, that daily knowledge depends on the type of exposure in the home, such as through parenting activities (playing with numbers, blocks), the availability of educational resources (books, computer games) and the time spent in child care which affect the level of early numeracy when the child enters school (Kleemans, Peeters, Segers, \& Verhoeven, 2012). The level of knowledge and learning progress also depends on the quality of the teacher-child interaction (Anders et al., 2012).

Teacher-child interaction will be conditioned by several factor as the class size, class climate, pupils behavior, staff qualification levels, and so on. Related with the last point and with our theoretical framework, the ability of the teacher to help the child or scaffolding his/her necessities in the learning process is a crucial element (Smit \& Van Eerde, 2011). Scaffolding can be understood as the responsiveness of the teacher (the assessor in DA) in order to guide a child towards the achievement in a specific task which would not been resolved by the child alone. Scaffolding also focuses on bringing the child to an independent state of competence and implies structure and contingency (Jadallah et al., 2011; Smit \& Van Eerde, 2013; Wood, Bruner, \& Ross, 1976). This concept is therefore deeply connected with ZPD (Cazden, 1979; Van Geert \& Steenbeek, 2005).

Nevertheless, the current study is specifically based on the Dynamic System Theory (DST) (Van Geert, 2008) interpretation of the processes taking place during scaffolding: the iterative nature of the process, that is, one step is the causal precondition for the next, in an iterative chain; the chain or process is a consequence of reciprocal reaction of child and adult; the adult tries to operate within a limited region of learn-ability, which is monitored/acted upon during each iterative step in the process; the process typically non-linear and variable over time, among others due to the fact that the steps of mutual adaptations of child and adult are characterized by relative uncertainty, leading to temporary over and under-adaptations, too close to or too far from what the child requires at that particular moment in terms of the temporary most adequate form of mediation. These principles also apply to any form of DA, and 
this fact requires that the actual process of adaptive testing should be studied, as it proceeds in the interaction between an individual tester and individual testee.

Therefore, scaffolding is not only determined by the teacher/assessor actions and, from a dynamic perspective, it is influenced by partners involved in the task, that is, the teacher and the child. The DST (Van Geert, 2008) is a self-organization of independent variables which are continuously interacting. The DST of scaffolding is a coupled dynamic model (see Van Geert \& Steenbeek, 2005) in which the current level of the child determines the scaffolding level and at same time the scaffolding level determines the new level of competence achieved by the child.

In this sense a micro-genetic approach allows a better view on how scaffolding proceeds during the mediation phase of a DA task. This methodology clarifies the dynamic interaction process by describing the interactions and observe whether patterns of interaction between the assessor and the child occur and if so whether they show specific relationships during the mediation phase. Furthermore, developing transition matrices allows us to show a graphical representation of the temporal structure of the process of interaction so that even whether they all lead to a certain net gain in a pretest-posttest setup, they will in all likelihood be very different for each assessor-child dyad, simply because they emerge on the basis of typically local (here-and-now) dynamics.

\section{Objectives}

For this purpose we selected the Classification subtest of the ACFS and we applied the micro-genetic approach to analyze the process of scaffolding in the mediation phase of the task. The first research question aimed at determining whether children profit from the scaffolding offered in the mediation phase. The second question investigated whether the mediation phase is tester-driven only or on the contrary unfolds a dynamic, reciprocal and unique scaffolding relationship to decide which scaffolding pattern fits best in wishing to improve the child's classification skills for educational purposes and, whether so, what temporal and structural (referring to the content and codes based on which the process is described and observed) forms the dynamic patterns take during the testing. 


\section{Method}

\section{Participants}

The participants in this research were four Dutch children in preschool age $\left(M_{\text {age }}=\right.$ 4.37, $S D=0.75)$. Two of them were boys and two of them were twin girls. All participants had a Spanish mother and a Dutch father, and they were able to speak and understand both languages. Children had been born and were growing up in the Netherlands in families with a high socio-economical status. All children were attending to their first year at primary school. Three boys were excluded of the study due to they did not speak Spanish.

\section{Instruments}

The Classification task is one of the six subtests from the Application Cognitive Functioning Scale (ACFS, Lidz \& Jensen, 2000, 2003; Spanish adaptation Evaluación de Habilidades y Potencial de Aprendizaje para Preescolares by Calero et al., 2009). The classification pretest as well as the posttest involves three tasks using 36 wooden blocks of different categories, shape, size and color. In this phase the child is asked to group the blocks, and if the child completes the grouping successfully in one of the three categories he/she is invited to group the blocks in a different way which means that the child is to change the category of classification. In case this action is executed successfully the child is invited to group the blocks in yet another and different way. In all three subsequent trials of classification can take place. When a child succeeds in less than three classifications the mediation phase is started: the child works with the assessor. The focus of the mediation phase is on helping the child to focus on attributes that allow classification by using two-dimensional cards that vary in shape, size and color allowing the child to discover the principle of classifying while carrying out the three tasks one after the other. The cards are located in front of the child. The assessor assists the child by offering performance feedback and helping with sorting depending on the child's progress to successfully execute the task. The interventions that can be offered by the assessor are semi-scripted and predetermined in order to impose a degree of standardization on the procedure: every child can get the same amount of mediation but not always needs it. After completion of the mediation phase the posttest is administered. The posttest is the same as the pretest. 
The maximum score for the pretest and posttest is 12 points distributed as follows: 3 points for building and structuring using the blocks ( 1 point whether the child only make a structure with them, 1 point whether the structure includes three or more shapes/sizes/colors, 1 point whether the structure shows symmetry). One point for grouping the blocks but without a defined category $/ 2$ points for grouping a few blocks following one or several categories, or 3 points for grouping all blocks in one or several categories. Finally, another 3 points can be obtained if the child regroups the blocks by changing the initial criteria for grouping. This scheme and the score system allow the assessor to establish the performance level of the child's cognitive ability (pretest) and his/her learning potential (gain score or the difference between posttest and pretest). The subtest Classification was involved in several validation studies obtaining a Cronbach alpha $=.79$.

\section{Procedure}

The assessments were carried out by the first author trained in DA procedures in Spanish and she was supervised by two observers. Each assessment was developed individually in one single session lasting 8 to 16 minutes, depending on the pretest performance level of the child and the necessity of the mediation phase. The subtest was videotaped with a camera on a stand. All children agreed with participation and had the informed agreement of their parents. To allow a micro-genetic data analysis the videotapes of the mediation phase were transcribed with regard to the tester and child behaviors during the test. Next, the behaviors were categorized with a coding system that was based upon two existing code systems (Ensing, van der Aalsvoort, \& van Geert, 2012; Van Loo \& Van der Aalsvoort, 2012) and adapted to allow coding of meaningful behaviors which emerged in the mediation phase of the Classification subtest (see Table 1).

\section{Table 1}

Categories to Code the Mediation Phase of Classification Task

\begin{tabular}{llc}
\hline & Executes the task correctly & \multicolumn{2}{c}{1} \\
\cline { 2 - 3 } The child responds to & Executes the task incorrectly & 2 \\
\cline { 2 - 3 } & Gives a response & 3 \\
\hline
\end{tabular}




\begin{tabular}{|c|c|c|c|}
\hline \multirow{5}{*}{ CHILD } & the mediation phase & Pays attention to the task & 4 \\
\hline & The child does not re- & Does not respond to the task & 5 \\
\hline & $\begin{array}{l}\text { spond to the mediation } \\
\text { phase }\end{array}$ & Does not pay attention & 6 \\
\hline & \multirow{2}{*}{ The child seeks support } & Shows that he/she does not know the solution & 7 \\
\hline & & Asks for attention & 8 \\
\hline \multirow{9}{*}{ ASSESSOR } & \multirow{6}{*}{$\begin{array}{c}\text { The assessor offers } \\
\text { support }\end{array}$} & Gives explanations, examples and proposals & A \\
\hline & & Activates the child's knowledge & B \\
\hline & & Gives instruction & $\mathrm{C}$ \\
\hline & & Responds to the child's initiative & $\mathrm{D}$ \\
\hline & & Modeling & $\mathrm{E}$ \\
\hline & & Guides the child's attention & $\mathrm{F}$ \\
\hline & $\begin{array}{c}\text { The assessor does not } \\
\text { offer support }\end{array}$ & Does not respond & G \\
\hline & The assessor motivates & Feedback & $\mathrm{H}$ \\
\hline & the child & Encourages the execution & I \\
\hline
\end{tabular}

Data Analysis

The InqScribe Analize Digital Media program (Inquirium, LLC. 2011; http://www.inqscribe.com) was employed to analyze the videotapes with the coding list by applying the codes to the behaviors by observing the videotapes and coding the behaviors simultaneously. After completion of the coding the information was exported to an Excel file which specified the behavioral codes both from the child and the assessor. The files allowed computation of the frequencies of the coded behaviors and the relationships between categories of codes.

\section{Results}

To answer the first research question determining the performance level in a task that assesses a basic cognitive function related with early numeracy and the learning potential showed after receiving brief mediated intervention, the raw scores obtained in the different 
phases of the Classification task were calculated for each child. These scores were compared with the data from the Spanish adaptation of the scale which allowed determining whether the level showed during the task was appropriate for preschool children. Table 2 shows the raw scores for each child. Data obtained showed a similar tendency in all cases, namely, all children obtained a pretest score which was situated in a medium range of performance and a posttest score which was at the high level, showing gains and therefore improvements of their execution in the task after receiving the mediation phase (see Table 2).

Table 2

Raw Scores Obtained in the Three Phases of the Classification Task of the ACFS for each Child

\begin{tabular}{cccc}
\hline & Pretest & Posttest & Gain score \\
\hline Boy 1 & 5 & 8 & 3 \\
\hline Boy 2 & 5 & 9 & 4 \\
\hline Girl 1 & 3 & 7 & 4 \\
\hline Girl 2 & 6 & 8 & 2 \\
\hline
\end{tabular}

The second question investigated whether the mediation phase is assessor-driven only or in the contrary unfolds a dynamic, reciprocal and unique scaffolding relationship to decide which scaffolding pattern fits best in wishing to improve the child's classification skills for educational purposes. For this purpose transition matrices were elaborated for each child from the score obtained by frequency analyses. The four matrices (Figure 1 to 4 ) show that each assessor-child unit had his/her own type of frequency patterns and, even further, it was possible to detect specific assessor's behaviors elicited by the child which supposedly fitted his concrete necessities.

\section{Boy 1}

The transition matrix for Boy 1 shows that the interaction between the assessor and the child was established in a systematic way. There was a clear pattern of scaffolding in which the assessor offered an explanation, example or proposal followed by the child's attention. Later on the assessor tended to activate the child's knowledge about the task which was fol- 
lowed by the boy's correct answer. In that case, the assessor offered positive feedback to the child in $60 \%$ of this type of interaction (see Figure 1).

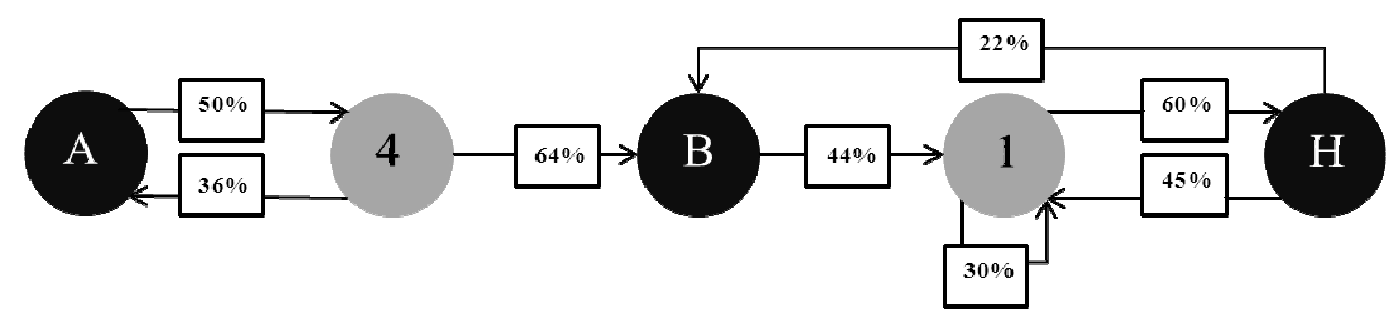

Figure 1. Matrix transition showing the frequencies of the behaviors and their relationships of Boy 1 and the assessor.

Note. $\mathrm{A}=$ the assessor gives explanations, examples and proposals; $\mathrm{B}=$ the assessor activates knowledge; $\mathrm{H}=$ the assessor gives feedback; 1 = the child executes the task correctly; $4=$ the child pays attention to the task

Partial transcript of Boy 1 (minute 05.33.26 to minute 06.36 .13 of the mediation phase):

Assessor: "So with these cards we can make more groups, can't we? You have already done the color group, grouping the red ones, the yellow ones, the blue ones, didn't you?"

Child: (nods and smiles)

Assessor: "okay"

Child: (the child looks at how the assessor is grouping the cards)

Assessor: "but we can do other groups"

Child: (nods)

Assessor: "for example, we can group the squares, the circles, the triangles, can't we?"

Child: (puts attention to the explanation and nods)

Assessor: "so, we can put together all the triangles, the squares..."

Child: (takes a card)

Assessor: "okay show me how could you do it?"

Child: (classifies the card correctly)

Assessor: "hey! very good!" 
The transcript suggests that the boy needed little scaffolding which was typically positively met by the assessor.

\section{Boy 2}

The transition matrix of Boy 2 reveals that the most frequent interaction includes that the assessor gives explanations, examples and proposals, and the child responds (50\%). Other patterns of interactions were revealed as well, such as when the explanations, examples and proposals are followed by different assessor behavior (activation of the child knowledge: $25 \%)$ or by a correct response from the child $(25 \%)$ which was reinforced in $41 \%$ of the interactions by the assessor (see Figure 2).

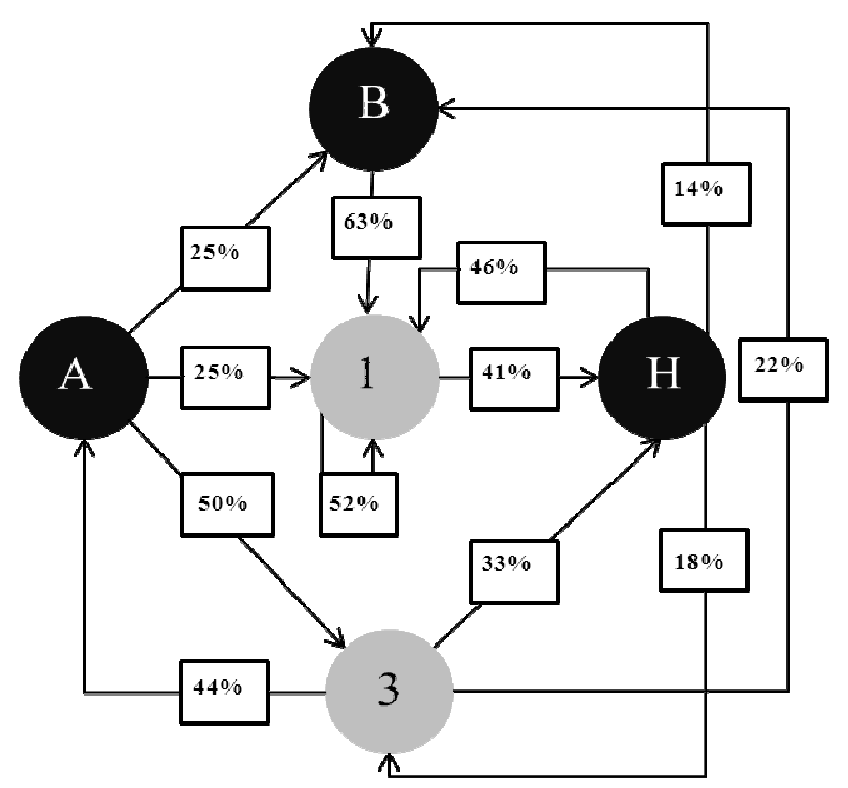

Figure 2. Matrix transition of the frequencies of behaviors and their relationships of Boy 2.

Note. $\mathrm{A}=$ the assessor gives explanations, examples and proposals; $\mathrm{B}=$ the assessor activates the knowledge; $\mathrm{H}$

$=$ the assessor gives feedback; $1=$ the child executes the task correctly; $3=$ the child responds 
Partial transcript of the Boy 2 (minute 04.00.06 to minute 04.39 .00 of the mediation phase) that reveals a typical pattern:

Assessor: "Look, we have just done the color group, the yellow ones, blue ones, red ones and green ones, haven't we?"

\section{Child: "yes"}

Assessor: "but, could we do more groups?"

\section{Child: “Uhm" (expressing doubt)}

Assessor: "I think so"

Child: "yes"

Assessor: "I will teach you another way"

\section{Child: (nods)}

Assessor: "look, this is a square, this is a circle, this is a triangle, isn't it? so with which of these has to go the square? (Pointing all the options)"

\section{Child: here (pointing the correct option)}

Assessor: "with the square, very good!"

Assessor: "and the triangle with the triangles" (grouping the cards)

Child: (the child starts to classify the cards correctly)

Assessor: "exactly"

The transcript suggests that the boy received instructions in order to focus him into the task, and through them, he can execute it correctly, without needing too much support.

\section{Girl 1}

The transition matrix for Girl 1 shows that the most frequent interaction involves that the assessor gives explanations, examples and proposals, and the child responds (60\%). Other two patterns of interactions also appeared: the explanations, examples and proposals are followed by the activation of the child knowledge (assessor behavior) (20\%), or by a correct response from the child (20\%). Moreover, this girl expresses in several moments of the interaction that she does not know to answer, which automatically elicits the activation of the previous knowledge by the assessor (100\%) (see Figure 3). 


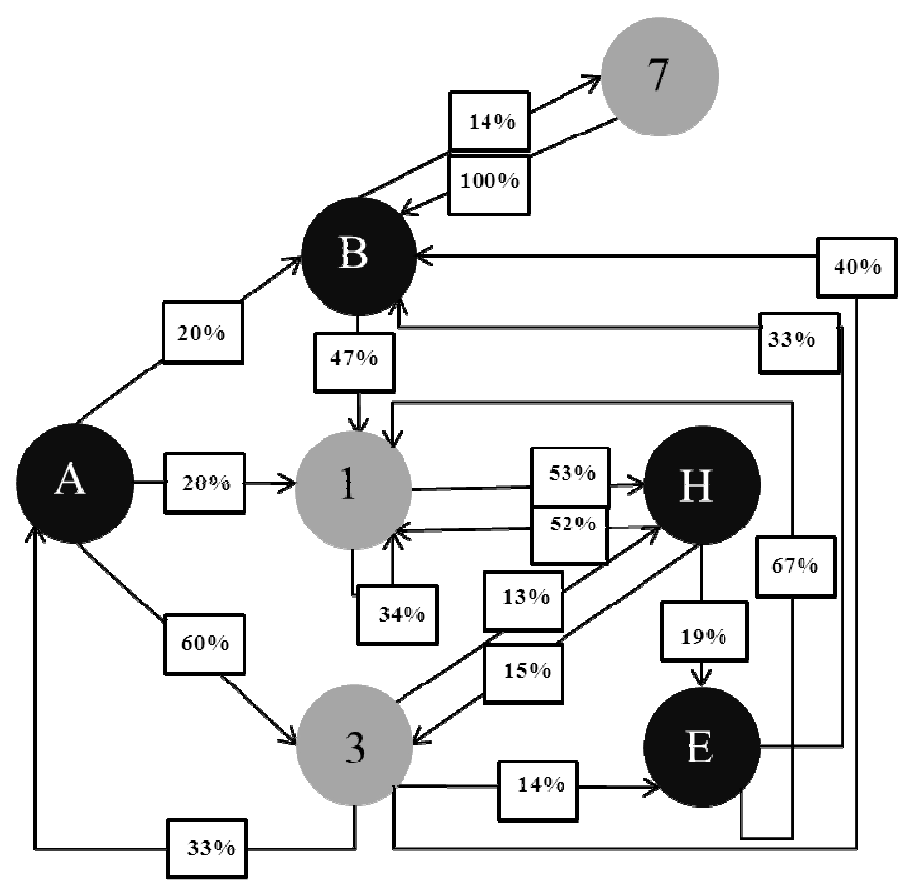

Figure 3. Matrix transition showing the frequency of the coding list behavior and their relationships in the mediation phase of the Classification task for the Girl 1

Note. $\mathrm{A}=$ the assessor gives explanations, examples and proposals; $\mathrm{B}=$ the assessor activates the knowledge; $\mathrm{H}$ $=$ the assessor gives feedback; $\mathrm{E}=$ the assessor models the child's behavior; $1=$ the child executes the task correctly; $3=$ the child responds; $7=$ the child shows that she does not know the solution

Partial transcript of Girl 1 (minute 03.39 .20 to minute 04.15 .00 of the mediation phase):

Assessor: "Can we make groups? Something different? look, for example we can put..., this is a square, isn't it?"

\section{Child: (nods)}

Assessor: "is this also a square?" (Pointing another card)

\section{Child: "yes"}

Assessor: "so we have to put it with the squares, haven't we? This is a cir..." (Pointing at a card and expecting the child to complete the word)

\section{Child: "circle"}

Assessor: "circle! So we have to put it with the circles. And it is a..." (Pointing a card and expecting the child to complete the word)

\section{Child: "Uhm" (does not know the answer)}


Assessor: "tria..." (Expecting the child to complete the word)

Assessor: "triangle"

\section{Child: "triangle"}

Assessor: (nods, showing that the answer is correct)

Assessor: "we have to put it with the triangles, haven't we? Okay, so we are doing the shape group. Come on, how can we make it?"

\section{Child: (takes a card and classifies it correctly)}

Assessor: "very good!"

In the case of Girl 1, the transcript shows how there are specific behaviors that appear to be needed for scaffolding: It is about activating her knowledge when she does not know the answer or modeling her behavior.

\section{Girl 2}

For Girl 2 the transition matrix shows that the most frequent interaction is that the assessor gives explanations, examples and proposals, and the child responds (55\%) followed by other two patterns: the explanations, examples and proposals are followed by the activation of the child knowledge (assessor behavior) (18\%), or by a correct response from the child (18\%). For this girl it is also possible to observe this behavior: when the assessor activates the knowledge she does not respond to the task. In these occasions the behaviors of the assessor are equally distributed between giving explanations, examples and proposals (50\%) and activating the child knowledge (50\%) (see Figure 4). 


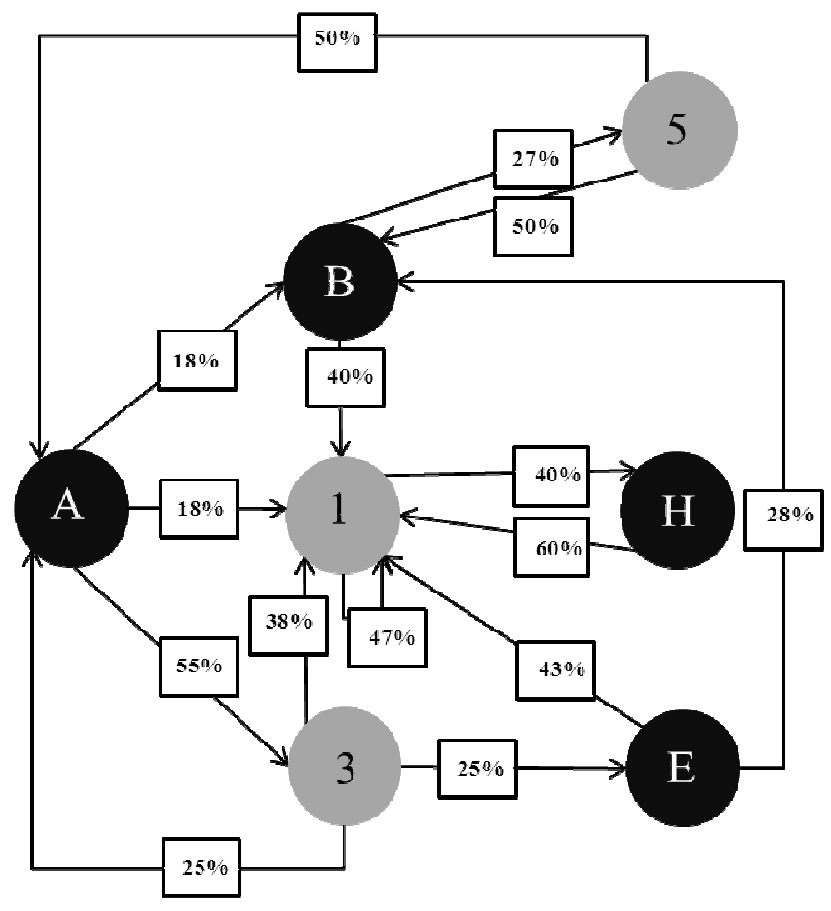

Figure 4. Matrix transition showing the frequency of the coding list behavior and their relationships in the mediation phase of the Classification task for the Girl 2

Note. $\mathrm{A}=$ the assessor gives explanations, examples and proposals; $\mathrm{B}=$ the assessor activates the knowledge; $\mathrm{H}$ $=$ the assessor gives feedback; $\mathrm{E}=$ the assessor models the child's behavior; $1=$ the child executes the task correctly; $3=$ the child responds; $5=$ the child does not respond to the task

Partial transcript of the Girl 2 (minute 03.25 .08 to minute 04.00 .06 of the mediation phase):

Assessor: "We can make different groups". "For example this is a...circle"

Child: (looks and nods to the assessor)

Assessor: "do you know it? Circle. And, this one?" (Showing another card)

Child: (does not respond)

Assessor: "tria...?"

\section{Child: "trianle" (the pronunciation is incorrect)}

Assessor: "triangle, very good" (the assessor modeling a close answer and reinforces it) Assessor: "and what is it?" (Showing a card)

Child: (gets up and looks at the cards that the assessor is holding, does not respond) Assessor: (shows a card to the child)

Child: (does not respond)

Assessor: "a squa..."

Child: "squre" (the pronunciation is incorrect)

Assessor: "square, isn't?" 


\section{Child: (nods)}

Assessor: "so come on, we can put all the equals together, the circles with the circles, the triangles" (Pointing a card with a triangle)

\section{Child: (takes the card and classifies it correctly)}

Assessor: "with the triangles"

Child: (nods)

Assessor: "and square with the square"

\section{Child: (takes the square card and classifies it correctly)}

Assessor: "Good! You already know how to do it!"

The transcript shows how Girl 2 avoids giving an answer when she does not know it and how the assessor tries to activate her knowledge and to model her behavior. The findings with regard to research the first question are that the 4 children were able to profit from the mediation phase of the Classification task of the ACFS, improving their execution in the posttest. In this sense, the 4 children achieve a high score after receive the mediation.

The answer to the second question is that it is possible to observe how the 4 dyads assessor-child established similar behaviors through the scaffolding of the mediation phase in the Classification task. Overall, the most usual behaviors for the assessor were always giving explanations, examples and proposals (code A), activating the knowledge (code B) and giving feedback (code H). Children tended to give an answer (code 3) and execute the task correctly (code 1). This structure could be reflecting the semi-scripted character of the task, showing how the assessor was following the instructions of the manual.

Nevertheless, despite of the similarities, matrices frequencies also show specific patterns of interaction which emerged as a particular response by the assessor to the necessities of the children, showing how the child is eliciting the scaffolding. In concrete, the assessorBoy 1 interaction was qualitative different from the rest of the dyads showing a minor necessity of scaffolding. Otherwise, Boy 2 and the twin girls showed very similar interaction patterns between them, although, the relations assessor-girls were more complex than between the assessor and Boy 2. In this line, it is interesting to observe how, in these girls, new behaviors appeared that seem to be related with feelings of doubt and those behaviors did not happen for the assessor-boys interactions. Another behavior that appeared in the assessor-girls interactions was modeling and in both cases was related with the responses gave by the girls, 
although the frequency of these behaviors was higher for Girl 1 than for Girl 2. Finally, it could be said that the feedback behavior showed more complex relationships with others variables for Girl 1 than for Girl 2. While for Girl 1 the feedback was related with a correct execution of the task, with responses given by the child and with modeling (by the assessor), the same reinforcement attitude was simpler for Girl 2 who reacted to it executing the task correctly.

\section{Discussion and Conclusions}

Results of this study have shown that the scaffolding applied in the mediation phase of a DA task generates significant improvements in the performance levels showed by the children in the posttest phase results which coincide with previous research (Calero et al., 2009; Calero et al., 2010; Lidz, 1992, 1997, 2004; Lidz \& Van der Aalsvoort, 2005; Tzuriel \& Haywood, 1992).

These results are important for the preschool stage because of having information not only about the current cognitive level of the child but also about his/her ability to profit from the mediation. Nevertheless, when the DST is applied into the mediation phase in order to study the dynamic of scaffolding it is possible to observe how it adapts to the special necessities of the child and therefore is also modified by he/she. It could be related to the fact that the semi-scripted mediation given by the manual of the ACFS is being adapted to each interaction process and generating a specific ZPD which generates the scaffolding for improving the learning. This fact could be seen in our findings which suggest that scaffolding is a personalized process that moves along the semi-scripted mediation procedure and reveal that children not only differ with regard to their potential to learn but also differ in their ability to elicit scaffolding from the assessor. In this sense the findings gathered by micro-genetic analysis shows a powerful way to extend suggestions for teachers not as a "here is the child, do this and this" in class or while interacting with him/her, but "here is this child". He/she will elicit from the teacher this type of behavior and when the teacher scaffolds has to make sure that is offering suggestions just once and waiting for his/her task behavior to appear before adding new suggestions (Boy 2, Girl 1 and 2). 
Application of the dynamic systems methodology data allows insight in how the assessor adapts mediation to each child as well as how the child elicits or awaits feedback which turns into specific patterns of interaction between assessor/child. The patterns that emerge are bidirectional, that is the assessor stimulates answers from the child but the unfolding scaffolding shows that the child also elicits behaviors from the assessor to fit his/her necessities (see also Ensing et al., 2012; Van der Aalsvoort et al., 2012).

Although this methodology can be applied to any content of curriculum we selected the Classification task of the ACFS because it has shown predictive validity of a numerical aptitude subtest in a longitudinal study (Mata \& Calero, 2014), confirming its power to predict the school success in mathematics (Anders et al., 2011; Aunio \& Niemivirta, 2010). So it seems that analyzing the temporal structure of the interaction between assessor/child through DST allows clarifying how the scaffolding is emerging and sustaining an individual learning in a task which is directly related with early numeracy abilities. In this sense, this type of information (learning process is not only managed by teachers but also by children implied) is crucial for the school staff who could analyze the importance of scaffolding in their relation with their pupils for achieving the curricular contents.

Moreover, applying this methodology with preschool children in a task which is related with one of the components of early numeracy might be a powerful indicator of the future performance in mathematics. The preschool age is itself a very important period for several reasons, one is that basic cognitive functions are being developed, another is that children are getting used to interact with formal educational environments. Together, preschool is an optimal stage in which determine what difficulties are children manifesting and develop preventive strategies in order to avoid possible future academic problems that emerge when they have to affront more complex academic contents. Counting with the knowledge of the DST applied to the scaffolding of the mediation phase in a Classification task is an evidence of the importance of the reciprocal learning for developing correct bases in components of early numeracy.

This study counts with several limitations that have to be mentioned. First, the small size of the sample. Although studies relies in the DST traditionally include small samples we could not incloud three boys due to they did not speak Spanish (the language in wich the assessment was carried on). Other characteristic that may have a direct impact in the results is 
the high socio-ecomic status of the participantes, something that could not be controlled due to the imposibility of including children from other socio-economics status. We point also as a limitation the fact of lacking of a control group (evaluation of pre-posttest, without mediation phase), which would have strengthened the results. Finally, we did not get access to the academic results (due to time limitation), which would have been very ilustrative, especially for Maths.

\section{References}

Akman, B., Ipek, A., \& Uyanik, G. (2000). Examination of the conceptual development of children at six years of age attending Kindergarten. International Journal of Early Childhood Education, 8(3), 227-234. http://dx.doi.org/10.1080/09669760050156767

Anders, Y., Rossbach, H. G., Weinert, S., Ebert, S., Kuger, S., Lehrl, S., \& Von Maurice, J. (2012). Home and preschool learning environments and their relations to the development of early numeracy skills. Early Childhood Research Quarterly, 27, 231-244. http://dx.doi.org/10.1016/j.ecresq.2011.08.003

Aunio, P., \& Niemivirta, M. (2010). Predicting children's mathematical performance in grade one by early numeracy. Learning and Individual Differences, 20, 427-435. http://dx.doi.org/10.1016/j.lindif.2010.06.003

Brown, A. L, \& Campione, J. C. (1986). Psychological theory and the study of learning disabilities. American Psychologist, 41, 1059-1068.

Budoff, M. (1987). Measures for assessing learning potential. In C. S. Lidz (Ed.), Dynamic Assessment (pp. 173-195). New York, NY: Guilford Press.

Calero, M. D., Carles, R., Mata, S., \& Navarro, E. (2010). Diferencias en habilidades y conducta entre grupos de preescolares de alto y bajo rendimiento escolar. Revista Electrónica de Investigación y Evaluación Educativa. R.E.L.I.E.V.E., 16 (2). http://www.uv.es/RELIEVE/v16n2/RELIEVEv16n2_5.htm. Accessed 03 December 2010 .

Calero, M. D., Fernández-Parra, A., López-Rubio, S., Carles, R., Mata, S., Vives-Montero, C., et al. (2013). Variables involved in personal, social and school adjustment in a sample of preschool-aged children from different cultural backgrounds. European Journal of Psychology of Education, 28, 133-155. http://dx.doi.org/10.1007/s10212012-0107-8 
Calero, M. D., Mata, S., Carles, R., Vives, C., López-Rubio, S., Fernández-Parra, A., et al. (2013). Learning potential and adaptation to the educational context: The usefulness of the ACFS for assessing immigrant preschool children. Psychology in the Schools, 50(7), 705-721. http://dx.doi.org/10.1002/pits.21701

Calero, M. D., Robles, M. A, \& García-Martín, B. (2010). Habilidades cognitivas, conducta y potencial de aprendizaje en preescolares con Síndrome de Down. Electronic Journal of Research in Educational Psychology, 8(1), 87-110.

Calero, M. D., Robles, M., Márquez, J., \& De la Osa, P. (2009). EHPAP: Evaluación de Habilidades y Potencial de Aprendizaje para Preescolares. Madrid: EOS.

Cazden, C. (1979). Peekaboo as an instructional model: Discourse development at home and at school. Palo Alto, CA: Stanford University Department of Linguistics.

Desoete, A., \& Grégoire, J. (2006). Numerical competence in young children and in children with mathematical learning disabilities. Learning and Individual Differences, 16, 351367. http://dx.doi.org/10.1016/j.lindif.2006.12.006

Ensing, A., van der Aalsvoort, G.M., \& van Geert, P. (2012). How dynamic patterns of teacher child interaction can provide insight in the learning potential of five year olds. In E. Hjörne, G. M. van der Aalsvoort, \& G. de Abreu (Eds.), Learning, social interaction and diversity-exploring identities in school practices (pp. 163-175). Rotterdam: Sense.

Ensing, A., van der Aalsvoort, G.M., van Geert, P., \& Voet, S. (2014). Learning Potential Is Related to the Dynamics of Scaffolding: An Empirical Illustration of the Scaffolding Dynamics of 5-Year-Olds and Their Teacher. Journal of Cognitive Education and Psychology, 13(3), 1-18. http://dx.doi.org/10.1891/19458959.13.3.1

Epstein, R. (1982). The myth of organisation. The Journal of mind and behavior, 3, 161-169.

Feuerstein, R., Klein, P. S., \& Tannenbaum, A. (1991). Mediated Learning Experience. London: Freund Publishing House, Ltd.

Haeussermann, E. (1958). Developmental potential of preschool children. New York, NY: Grune and Stratton.

Jadallah, M., Anderson, R. C., Nguyen-Janiel, K., Miller, B. W., Kim, I. H., Kuo, L. J., \& $\mathrm{Wu}, \mathrm{X}$. (2011). Influence of a teacher's scaffolding moves during child-led smallgroup discussion. American Educational Research Journal, 48(1), 194230. http://dx.doi.org/10.3102/0002831210371498 
Kleemans, T., Peeters, M., Segers, E., \& Verhoeven, L. (2012). Child and home predictors of early numeracy skills in kindergarten. Early Childhood Research Quarterly, 27, 471477. http://dx.doi.org/10.1016/j.ecresq.2011.12.004

Krajewski, K., \& Schneider, W. (2009a). Early development of quantity to number-word linkage as a precursor of mathematical school achievement and mathematical difficulties: Findings from a four-year longitudinal study. Learning and Instruction, 19(6), 513-526. http://dx.doi.org/10.1016/j.learninstruc.2008.10.002

Lidz, C. S. (1990). The Preschool Learning Assessment Device: An approach to the dynamic assessment of young children. European Journal of Psychology of Education, 2, 167175. http://dx.doi.org/10.1007/BF03172680

Lidz, C. S. (1992). Extent of incorporation of dynamic assessment in cognitive assessment courses: A national survey of school psychology trainers. Journal of Special Education, 26(3), 325-331. http://dx.doi.org/10.1177/002246699202600307

Lidz, C. S. (1997). Dynamic assessment approach. In D. P. Flanagan, J. L. Genshaft, \& P. L. Harrison (Eds.), Contemporary intellectual assessment. Theories, test and issues (pp. 281-296). New York, NY: Guilford Press.

Lidz, C. S. (2004). Assessment procedure with deaf student between the ages of four and eight years. Educational and Child Psychology, 21(1), 59-73.

Lidz, C. S. (2005). Dynamic assessment with young children: We've come a long way baby! Journal of Early Childhood and Infant Psychology, 1, 99-112.

Lidz, C. S., \& Gindis, B. (2003). Dynamic assessment of the evolving cognitive functions in children. In A. Kozulin, B. Gindis, V. S. Ageyev, \& S. M. Miller (Eds.), Vygotsky’s educational theory in cultural context. Cambridge: Cambridge University Press.

Lidz, C. S., \& Jepsen, R. H. (2000). The Application of Cognitive Function Scale (ACFS). Unpublished manuscript.

Lidz, C. S., \& Jepsen, R. H. (2003). Application of Cognitive Functions Scale (ACFS): Technical manual. Unpublished manuscript.

Lidz, C. S., \& Thomas, C. (1987). The Preschool Learning Assessment Device: Extension of a static approach. In C. Lidz (Ed.), Dynamic Assessment: An international approach to evaluating learning potential (pp. 288-326). New York, NY: Guilford Press.

Lidz, C. S., \& van der Aalsvoort, G. M. (2005). Usefulness of the Application of Cognitive Functions Scale with young children from the Netherlands. Transylvanian Journal of Psychology, 1, 82-99. 
Mata, S., \& Calero, M.D. (2014). Dynamic assessment: The Spanish version of the Application of Cognitive Functions Scale. The Spanish Journal of Psychology, 17, 1-9. http://dx.doi.org/10.1017/sjp.2014.98.

Passolunghi, M. C., Vercelloni, B., \& Schadee, H. (2007). The precursors of mathematics learning: Working memory, phonological ability, and numerical competence. Cognitive Development, 22, 165-184. http://dx.doi.org/10.1016/j.cogdev.2006.09.001

Quinn, P.C. (2004). Early categorisation: A new synthesis. In U. Goswami (Ed.), Blackwell handbook of childhood cognitive development (pp. 84-101). Oxford, UK: Blackwell Publ. Ltd.

Schucman, H. (1960). Evaluating the educability of the severely mentally retarded child. Psychological Monographs, 74 (14, whole No. 501). http://dx.doi.org/10.1037/h0093762

Shapiro, M. B. (1951). An experimental approach to diagnostic psychological testing. Journal of Mental Sciences, 97, 748-764. http://dx.doi.org/10.1192/bjp.97.409.748

Smit, J., \& Van Eerde, D. (2011). A teacher's learning process in dual design research: Learning to scaffold language in a multilingual mathematics classroom. ZDM-The International Journal on Mathematics Education, 43, 889-900. http://dx.doi.org/ 10.1007/s11858-011-0350-5

Smit, J., \& Van Eerde, D. (2013). What counts as evidence for the long-term realisation of whole-class scaffolding? Learning, Culture and Social Interaction, 2, 22-31. http://dx.doi.org/10.1016/j.lcsi.2012.12.006

Tzuriel, D., \& Haywood, H. C. (1992). The development of interactive-dynamic approaches for assessment of learning potential. In H. C. Haywood, \& D. Tzuriel (Eds.), Interactive Assessment (pp. 3-37). New York, NY: Springer-Verlag.

Van den Heuvel-Panhuizen, M., \& Wijers, M. (2005). Mathematics standards and curricula in the Netherlands. ZDM-The International Journal on Mathematics Education, 37(4), 287-307. http://dx.doi.org/10.1007/BF02655816

Van der Aalsvoort, G.M., van Loo, F., \& van Geert, P. (2012). Scaffolding: Meaningful Sequences during the Training Phase of a Learning Potential Test? ISRN Education, 1. http://dx.doi.org/10.5402/2012/456094

Van Geert, P. (2008). The Dynamic Systems approach in the study of L1 and L2 acquisition: An introduction. The Modern Language Journal, 92(2), 179-199. http://dx.doi.org/10.1111/j.1540-4781.2008.00713.x

Van Geert, P., \& Steenbeek, H. (2005). The dynamics of scaffolding. New Ideas in Psychology, 23, 115-128. http://dx.doi.org/10.1016/j.newideapsych.2006.05.003 
Volle, F. O. (1957). A proposal for "testing the limits" with mental defectives for the purpose of subtest analysis of the WISC verbal scale. Journal of Clinical Psychology, 13(1), 64-67. http://dx.doi.org/10.1002/1097-4679(195701)13:1<64::AIDJCLP2270130116>3.0.CO;2-1

Vygotsky, L. S. (1978). Mind in society. Cambridge, MA: Harvard University Press.

Wiedl, K. H., Kampling, V., Koenig, I., Schevels, E. M., Waldorf, M., \& Carlson, J. S. (2011, July). Adapting the Application of Cognitive Functions Scale (ACFS) for use in German speaking countries. Paper presented at the 13th Biannual Conference of the International Association for Cognitive Education and Psychology, Boston, USA.

Wiedl, K. H., Mata, S., Waldorf, M., \& Calero, M. D. (2014). Dynamic testing with native andmigrant preschool children in Germany and Spain, using the Application of Cognitive Functions Scale. Learning and Individual Differences, 35, 34-40. http://dx.doi.org/10.1016/j.lindif.2014.07.003

Wood, D., Bruner, J., \& Ross, G. (1976). The role of tutoring in problem-solving. Journal of Child Psychology and Psychiatry, 17(2), 89-100. http://dx.doi.org/10.1111/j.14697610.1976.tb00381.x 